\title{
A Step Forward to Ignition in Inertial Confinement Fusion Experiments at National Ignition Facility
}

DOI: $10.3938 /$ PhiT. 23.019

Hye-Sook PARK

Thermonuclear fusion of hydrogen nuclei into helium is the basic principle under which the sun generates energy. Duplicating this process in the laboratory will give a new physics regime in the laboratory and is of interest for fusion energy. Laser driven inertial confinement fusion is a possible method for achieving this goal. Recently, for the first time, the National Ignition Facility in Livermore, CA, USA, reported obtaining a higher energy output than the amount of energy input into the targets fusion fuel. ${ }^{[1-4]}$ This was accomplished by a judicious tuning of the laser beam profile to dampen the hydrodynamic instabilities that cause unwanted mixing of the plastic capsule shell into the hydrogen fuel. While this energy output is only small fraction $(\sim 1 \%)$ of the total laser input energy and thus far from what is needed for energy applications, it signals a significant step forward in the understanding of the relevant physics phenomenon that occurs under high pressure and high temperatures.

수소 원자핵이 헬륨으로 바뀌는 열 핵융합은 태양이 에너지 를 생산하는 기본 원리다. 이 과정을 실험실에서 재현하는 것 은 지상에서 청정 에너지원을 개발한다는 목표에 더욱 접근하 는 것이다. 레이저에 의한 관성 봉입 핵융합(inertial confinement fusion, $\mathrm{ICF}$ )은 이 목표를 성취하는 가능한 방법 중 하 나다. 최근 미국 캘리포니아 리버모어의 국립 발화 장치(the National Ignition Facility, NIF)에서는 핵융합을 일으키는 타 깃에 투입되는 에너지의 양보다 더 많은 에너지가 방출되었다 고 보고했다. ${ }^{[1-4]}$ 이는 레이저 빔을 적절히 조정해서, 플라스틱 캡슐 껍질이 수소 연료에 섞이게 하는 유체역학적 불안정성을

\section{저자약력}

Dr. Hye-Sook Park is a physicist at Lawrence Livermore National Laboratory. She received her Ph. D. from University of Michigan, Ann Arbor, Ml. After a post-doctoral work at Univ. of California, Berkeley, CA, she has been working at LLNL since 1987. Her research includes many areas of high energy density physics. She is a Fellow of the American Physical Society since 2010 (park1@\|lnl.gov)

\section{Deuteron \\ Helium}

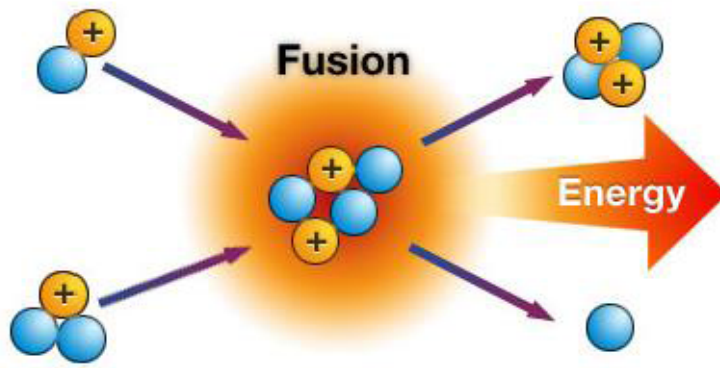

Triton

Neutron

Fig. 1. Nuclear fusion reaction where deuterium and triton fuse into Helium atom and a neutron producing energy from the remaining mass amount.

줄임으로써 얻을 수 있다. 이 방출되는 에너지는 투입되는 전 체 레이저 에너지의 아주 작은 부분 $(\sim 1 \%)$ 이고 따라서 실제 로 작동하는 핵융합 발전소에 필요한 정도와는 거리가 멀지만, 고압, 고온 상태에서 일어나는 관련 있는 물리 현상을 이해하 는데 의미있는 걸음을 내딛었음을 가리킨다.

핵융합은 두 종류의 수소 원자가 결합하여 더 무거운 헬륨 원자로 만들어질 때 일어나고, 그 과정에서 작은 질량 차이가 에너지로 나오게 (변환하게) 된다(그림 1). 두 수소 원자 사이 의 쿨롱 반발력을 넘어서기 위해서는 태양 중심에서처럼의 많 은 열과 압력이 필요하다. Fusion ignition은 핵융합에서 나오 는 에너지가 핵융합에 필요한 에너지와 같거나 더 많은 제어

\section{REFERENCES}

[1] H.-S. Park, O. Hurricane, D. Callahan, D. Casey, E. Dewald, T. Dittrich, T. Döppner, D. Hinkel, L. Berzak Hopkins, S. Le Pape, T. Ma, P. Patel, B. Remington, H. Robey, J. Salmonson and J. Kline, Phys. Rev. Lett. 112, 055001 (2014).

[2] T. Dittrich, O. Hurricane, D. Callahan, E. Dewald, T. Döppner, D. Hinkel, L. Berzak Hopkins, S. Le Pape, T. Ma, J. Milovich, J. Moreno, P. Patel, H.-S. Park, B. Remington, J. Salmonson and J. Kline, Phys. Rev. Lett. 112, 055002 (2014).

[3] O. A. Hurricane, D. A. Callahan, D. T. Casey, P. M. Celliers, C. Cerjan, E. L. Dewald, T. R. Dittrich, T. Döppner, D. E. Hinkel, L. F. Berzak Hopkins, J. L. Kline, S. Le Pape, T. Ma, A. G. MacPhee, J. L. Milovich, A. Pak, H.-S. Park, P. K. Patel, B. A. Remington, J. D. Salmonson, P. T. Springer and R. Tommasini, Nature 506, 343 (2014).

[4] S. Rose, Physics 7, 13 (2014). 


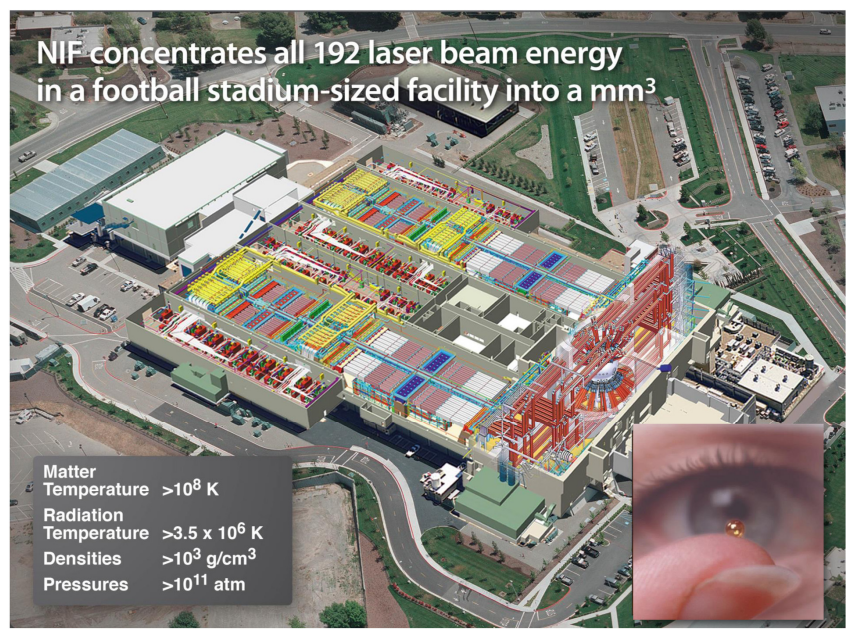

Fig. 2. National Ignition Facility in Livermore, California, USA. The 192 laser beams with up to $500 \mathrm{TW}$ and $1.9 \mathrm{MJ}$ energy can focus into a $2 \mathrm{~mm}$ diameter capsule to create high pressure and high temperature environment adequate for thermonuclear ignition environment.

된 연쇄 핵융합이 일어나는 순간을 가리킨다.

Ignition을 달성하는 것은 세상을 위한 무한 새 청정에너지의 길을 열 것이다. 1950 년대부터 핵융합을 이루기 위해 많은 과 학자들이 연구에 연구를 거듭해오고 있다. 제어 가능한 핵융합 을 이루기 위해 다양한 방법들이 연구되고 있는데, 그 중에서 magnetic confinement fusion $(\mathrm{MCF})^{[5,6]}$ 과 관성 봉입 핵융합 ${ }^{[7,8]}$ 이 핵융합을 이룰 가능성이 높다. 이 글은 관성 봉입 핵융합에 중 심을 두고 있다.

$\mathrm{NIF}^{[9]}$ 는 세계에서 가장 커다란 레이저 장치로 미국 캘리포니 아주 리버모어시에 있는 국립로렌스리버모어연구소(Lawrence Livermore National Laboratory)에 자리잡고 있다. 이는 192개 의 레이저 빔으로 이루어져 있고, $351 \mathrm{~nm}$ 파장의 빛이 최대 1.9 $\mathrm{MJ}$ 에너지, $500 \mathrm{TW}$ 를 목표에 전달할 수 있다. 레이저 증폭 장치(laser amplification)와 타겟 챔버(target chamber)는 미식 축구장 세 개 넓이에 일반 건물 10 층에 달하는 건물에 지어졌 다(그림 2). 타겟 챔버는 지름이 $10 \mathrm{~m}$ 에 달하고 레이저와 다 양한 관측기를 위해 많은 연결부(Port)가 있다(그림 3). NIF 건설은 1997년에 시작했고, 핵융합을 위한 최대가동(full-scale) 실험은 2009년에 처음으로 시작했다. 그때부터 지금까지 무려 1000 회 이상의 실험이 진행됐다.

관성 봉입 핵융합은 중수소(deuterium)와 삼중 수소(tritium) 로 이루어진 작은 공 모양의 연료 표적을 가열하고 압축해서 핵융합을 이루고 그 과정에서 에너지를 얻기 위한 것이다. Ignition을 이루기 위해서는 중수소-삼중수소(deuterium-tritium, DT) 연료에 목표 $350 \mathrm{Gbar}$ 의 압력, $1000 \mathrm{~g} / \mathrm{cm}^{3}$ 의 밀도가 필요하고, 중심 온도는 5 천만 도 이상이 되어야 한다. 연료의 압축은 연료 표피가 가열에 의해 빠른 속도로 외부로 떨어져

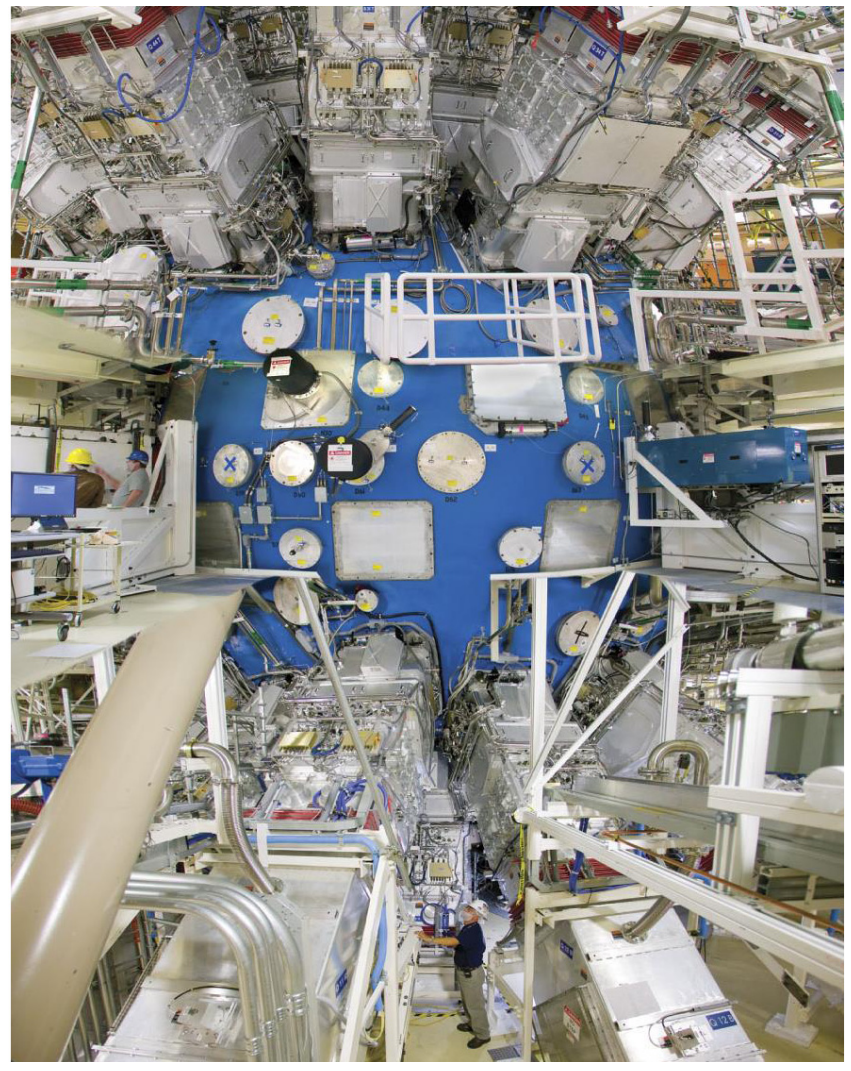

Fig. 3. Ten-meter NIF target chamber (blue section) and some beam ports and diagnostic ports.

나올 때 생기는 압력이 연료 내부로 전달되면서 이루어진다. 연료를 가열하는 방법에는 레이저로 연료를 직접 가열하는 방 식(direct heating)과 연료를 둘러싸고 있는 통을 레이저로 가 열하고 이때 나오는 $\mathrm{x}$ 선을 이용하여 간접적으로 연료를 가열 하는 방식(indirect heating)이 있다.

지금 $\mathrm{NIF} \mathrm{ICF} \mathrm{연구는} \mathrm{간접} \mathrm{가열} \mathrm{방식이} \mathrm{중점으로} \mathrm{이루어지}$ 고 있다. 그림 4는 바로 이 간접 가열 방식 실험의 단면도를 보여주고 있다. 이 도면에서 $\mathrm{NIF}$ 레이저가 작은(길이 약 1 $\mathrm{cm}$, 지름 $0.575 \mathrm{~cm}$ ) 원통 모양의 무거운 원소(금)로 만들어진 통에 (이 통은 홀럼(hohlraum)이라고 불린다) 양쪽에 있는 구 멍을 통해 들어가고 있다. 레이저가 들어가기 위한 두 개의 구 멍(laser entrance holes, LEHs)의 지름은 원통 지름의 절반

\section{REFERENCES}

[5] A. H. Boozer, Review of Modern Physics 76, 1071 (2005).

[6] R. Betti et al., Physics of Plasmas 17, 058102 (2010).

[7] J. Nuckolls, L. Wood, A. Thiessen and G. Zimmerman, Nature 239, 139 (1972).

[8] J. D. Lindl, Inertial Confinement Fusion (American Institute of Physics, 1998).

[9] E. I. Moses and C. R. Wuest, Fusion Science and Technology 47, 314 (2005). 

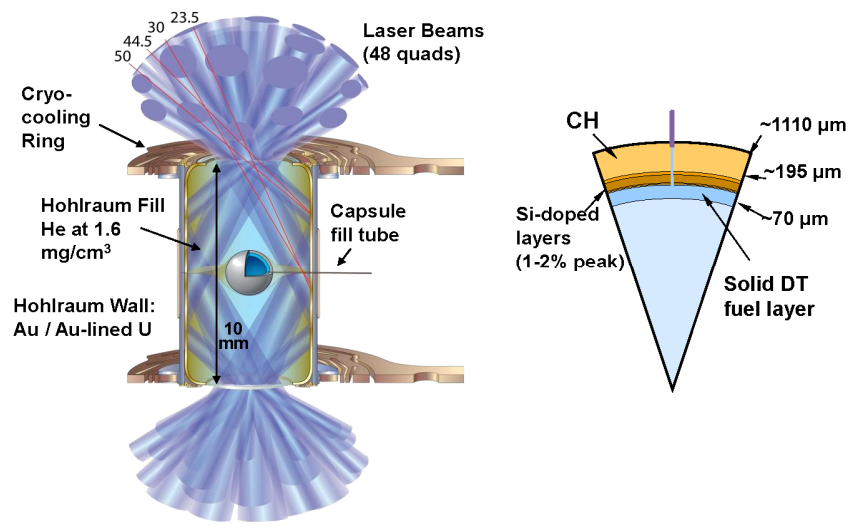

Fig. 4. The Deuterium-tritium (DT) experimental platform. The $2 \mathrm{~mm}$ capsule is placed at the center of a gold hohlraum. The laser creates soft $x$-ray oven to ablate the capsule to compress the fuel layer of DT ice and to raise the temperature of the hot spot at the center. ${ }^{[10]}$

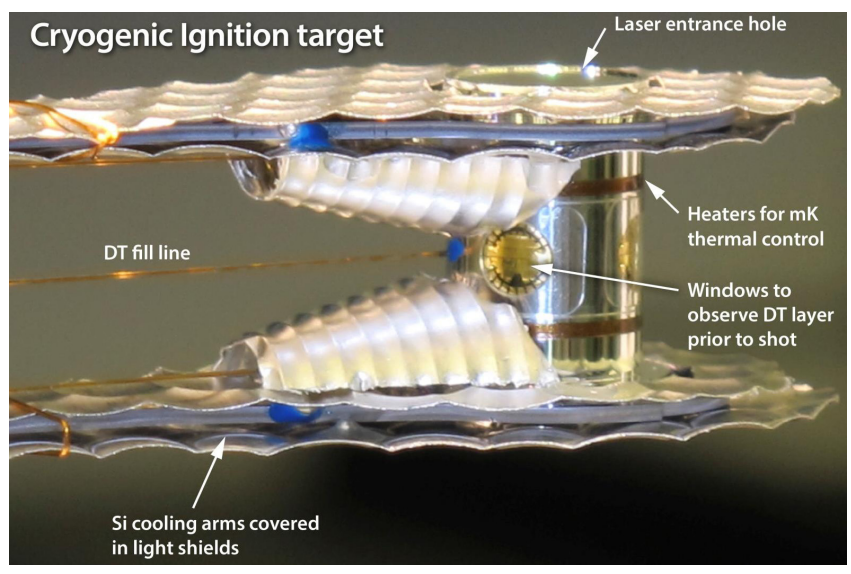

Fig. 5. An assembled DT target. A $\sim 2.2 \mathrm{~mm}$ diameter DT fuel capsule is centered inside $\sim 10 \mathrm{~mm}$ tall and $\sim 6 \mathrm{~mm}$ diameter cylindrical gold hohlraum.

정도이다. 원통(홀럼)의 내부 표면을 균일하게 비추기 위해 각 기 다른 입사각으로 96 개의 레이저 빔이 양쪽에서 진입하게 된다. 홀럼 내부 표면으로부터의 금 플라스마가 급속도로 확장 되는 것을 막기 위해, 홀럼 내부는 $1.6 \mathrm{~g} / \mathrm{cm}^{3}$ 밀도와 $19 \mathrm{~K}$ 의 헬륨가스로 채워져 있다. 홀럼 중심에 있는 캡슐(capsule)은 약 $45 \mathrm{~nm}$ 두께의 얇은 막(membrane)으로 고정되어 있다. 캡 슐 지름은 약 $2.2 \mathrm{~mm}$ 이고 약 $195 \mu \mathrm{m}$ 두께의 $\mathrm{CH}$ (plastic) 표피가 둘러싸여져 있다. 금으로부터 나오는 M-band x선을 막기 위해서 $\mathrm{CH}$ 의 $195 \mu \mathrm{m}$ 두께 중에 약 $50 \mu \mathrm{m}$ 는 함량 1 $2 \%$ 의 silicon이 섞여있다. 하나의 고체 크리스탈인 DT 연료층 은 $69 \mu \mathrm{m}$ 두께로 $18.3 \mathrm{~K}$ 의 극저온으로 챔버 안에서 바로 만 들어진다. 그림 5 는 완성된 타겟을 보여주고 있다. 여기에는 DT 연료층의 두께와 표면을 관찰하기 위한 관찰구(diagnostic windows), 열 제어 선(thermal control line), 그리고 전환이 되지 않은 레이저를 막기 위해 고안된 홈들이 파진 보호막

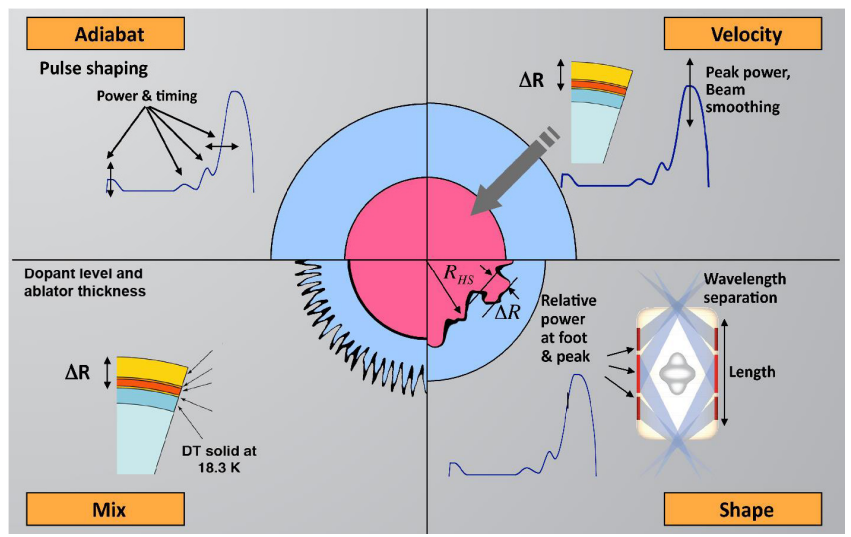

Fig. 6. A schematic view of required parameters for ignition. During the implosion, the capsule needs to maintain symmetric shape, high velocity, low adiabat and low mix to achieve ignition. [M. J. Edwards, et al., Phys. Plasmas 18, 051003 (2013).]

(dimpled shields)이 같이 포함되어 있다.

내파(implosion)에 의한 압축 과정 중 캡슐(capsule)의 모양 의 대칭, 레이저 파워 제어를 통한 빠른 속도의 박리(ablation) 유지, 레이저 빔 전달 제어, 압축 과정 중 유체역학적 불안정 성에 의한 캡슐 박리층이 고온의 캡슐 중심에 섞이는 것을 억 제하고 동시에 단열과정에서(adiabat) 최소한의 엔트로피를 유 지함으로써 가능한 최대한의 레이저 에너지를 연료 압축 속도 (compression velocity)로 전환하는 것 등이 ignition을 달성하 기 위한 네 개의 중점 요소다. 이 네 개 분야는 모두 레이저가 플라스마 속에서 어떻게 서로 영향을 주고받는지에 대한 이해 와 시공간에서의 특정 모양의 레이저를 만듦으로써 레이저가 정확히 전달되게 하고, 타겟 제작, 섬세한 물리적 설계(physics modeling), 그리고 초고온 초압력에서 정확히 예측을 할 수 있 는 모의실험(simulation)을 필요로 한다. 상세한 정보는 기재된 논문들을 참고하기 바란다. ${ }^{[10,11]}$

지난 몇 년간 이루어진 많은 DT 타겟 실험들은 이상적인 낮은 단열 펄스 모양에 중점을 두고 이루어졌다. 이 펄스 모양 은 로우풋(low-foot)이라 불리는 낮은 파워의 레이저 펄스가 먼 저 연료 타겟에 도달하고, 낮은 단열과정에서 $(\alpha \sim 1.5)$ 연료를 가열(drive)할 수 있도록 시차와 파워가 조정된 세 개의 레이저 펄스가 뒤따르게 이루어져 있다. 이 실험들은 빠른 속도의 내 파와 높은 DT 연료 단위 면적당 밀도 $(\rho R)$ 를 이루었지만 측정 된 이득(yield)은 1 차원 모의실험 결과에는 미치지 못했다. ${ }^{[12]}$

최근에 이루어지고 있는 하이풋(high-foot) 실험은 내파의 성

\section{REFERENCES}

[10] S. W. Haan et al., Physics of Plasmas 18, 051001 (2011).

[11] O. L. Landen et al., Physics of Plasmas 18, 051002 (2011).

[12] M. J. Edwards et al., Physics of Plasmas 20, 070501 (2013). 


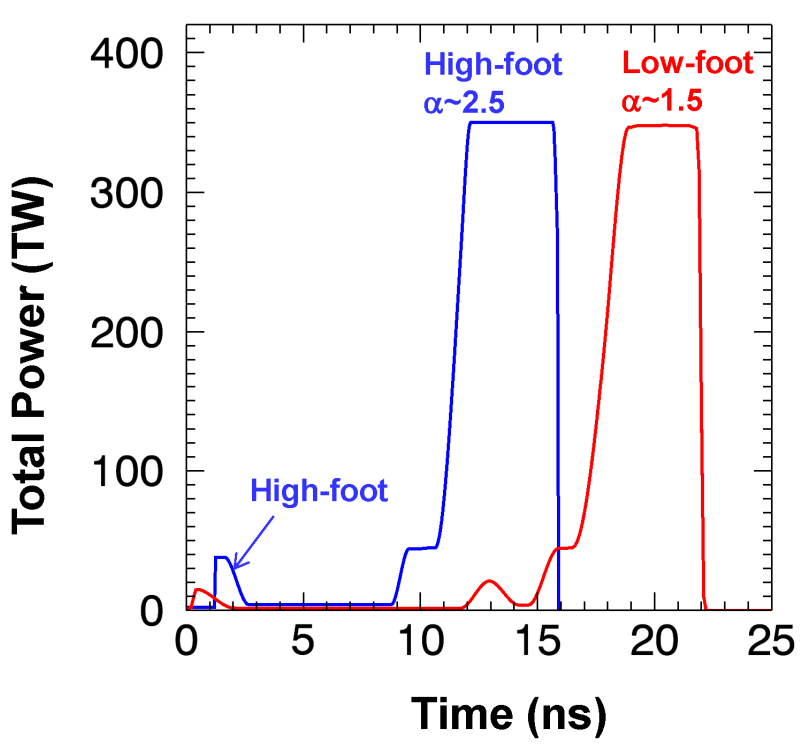

Fig. 7. Pulse shapes for low-foot and high-foot. The high-foot has high power initial starting push to mitigate the hydrodynamic instabilities.
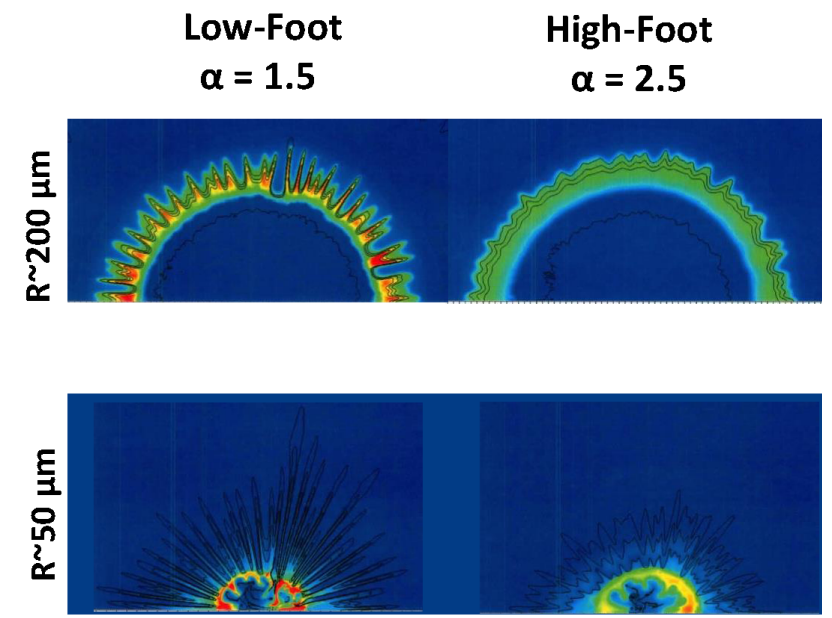

Fig. 8. Simulation results show that the high-foot high-adiabat implosion will reduce the ablation-front hydrodynamic instabilities. ${ }^{[2]}$

능(performance)을 올리기 위해 (타켓 캡슐) 성분들이 섞이는 것을 방지하는데 중점을 두고 있다. 모의실험에 따르면 많은 양의 파워를 첫 레이저 펄스에 주입할 경우에 단열선은 올라 가지만 (increase in adiabat) 유체역학적 불안정성 증가가 상 당히 낮아질 것이라는 결과가 나왔고, 이에 바탕을 두고 레이 저 펄스를 조정한 것이 바로 하이풋 실험이다. 그림 7 은 두 종류(로우풋과 하이풋) 레이저 펄스의 차이점을 보여주고 있다. 그림 8은 로우풋과 하이풋이 어떻게 ablation front instability 에 영향을 주는지에 대한 모의실험(simulation) 결과를 보여주고 있다. 위쪽 사진은 연료 캡슐의 반지름이 약 $200 \mu \mathrm{m}$ 때의 결 과이고, 핵융합 시점(bang time)에 가까울 때 캡슐의 반지름이 $50 \mu \mathrm{m}$ 에 달하는 것이 아래 사진에 보인다.

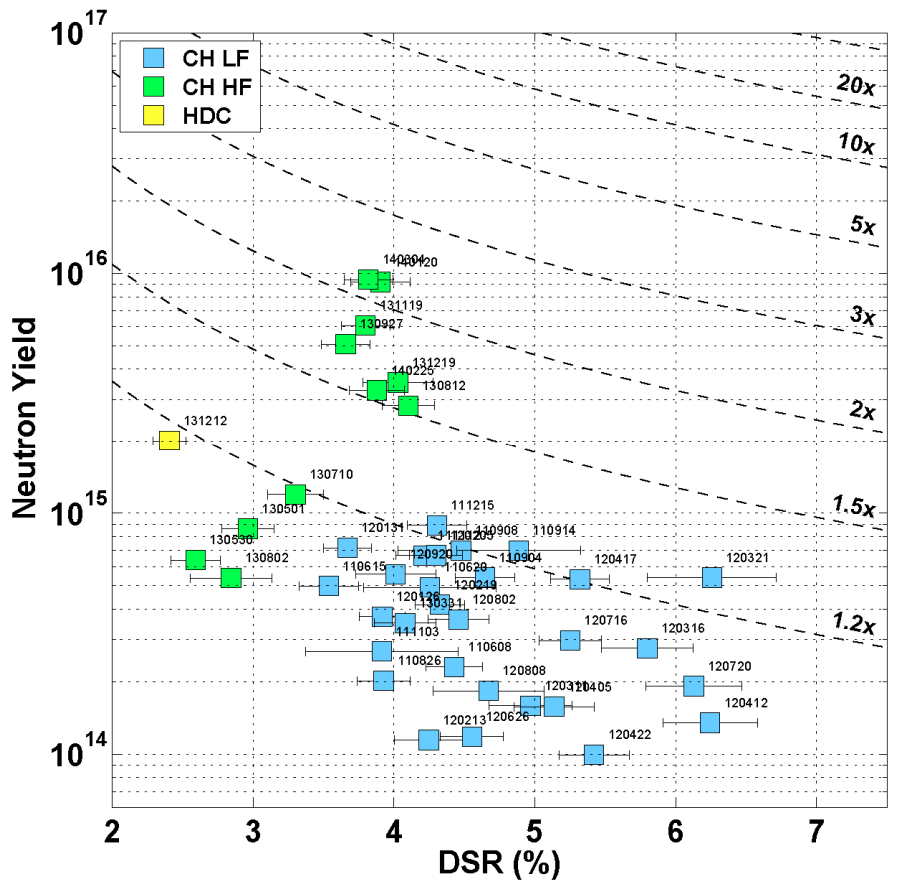

Fig. 9. Implosion performance of high-foot DT shots. Near $10^{16}$ neutron yields are achieved. The blue data points are the low-foot data; the yellow point is done with a diamond capsule and the high-foot data points are marked in green. [B. K. Spears, P. K. Patel and J. D. Lindl, Private communication (2014).]

내파의 성능은 $\mathrm{NIF}$ 를 여러 번 진단해서 측정한다. 중성자 이득과 스펙트럼은 중성자 비행시간(NTOF) ${ }^{[13]}$ 중성자 활성화 검출기(NADs) ${ }^{[14]}$ 그리고 자기 반동분광계(MRS) 검출기 ${ }^{[15]}$ 로 측정한다. 과열점과 연료의 모양은 $\mathrm{X}$ 선 카메라 ${ }^{[16]}$ 와 중성자 계 측기(neutron imager) ${ }^{[17]}$ 로 측정한다. 폭발 시간은 X선 연속 카메라와 남극 폭발시간 검출기로 측정한다. ${ }^{[18]}$ 실험에서 측정 한 모든 것을 모아서 개개 시도의 내용 변수를 유도해낸다.

하이풋 실험 결과는 로우풋 실험 결과보다도 10 배 정도 성능이 높다. 적정한 down-scattered-ratio (DSR)를 유지하고 중성자 이득을 지속적으로 올린 하이풋 실험들의 결과가 그림 9에 보이고 있다. DSR는 $10 \sim 12 \mathrm{MeV}$ 에너지의 중성자 수 를 13 15 MeV 에너지의 중성자 수로 나눈 것으로 연료가

\section{REFERENCES}

[13] V. Y. Glebov et al., The Review of Scientific Instruments 81 , 10D325 (2010).

[14] D. L. Bleuel et al., The Review of Scientific Instruments 83, 10D313 (2012).

[15] M. Gatu Johnson et al., The Review of Scientific Instruments 83, 10D308 (2012).

[16] P. M. Bell et al., The Review of Scientific Instruments 81, 10E540 (2010).

[17] G. P. Grim, et al., Physics of Plasmas 20, 056320 (2013).

[18] D. H. Edgell et al., The Review of Scientific Instruments 83, $10 \mathrm{E} 119$ (2012). 


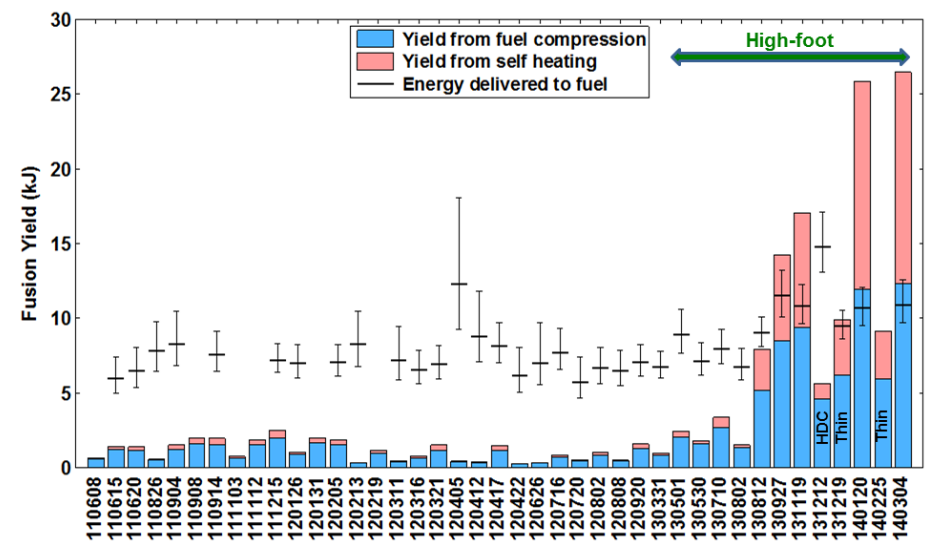

Fig. 10. Alpha heating yield vs. compressional yield of all the DT layered shots. N131212 (marked as HDC) was a diamond capsule shot and N131219 and N140225 used thinner capsule thickness. The high-foot shots achieved the fuel gain (the energy output from the fuel over the energy input) greater than unity. [B. K. Spears, P. K. Patel and J. D. Lindl, Private communication (2014).]

얼마나 압축됐는지를 보여준다. (계산에 따르면) 천억 분의 1 그램보다도 적은 양의 (천만 분의 1 그램 이하) 박리층 성분 (ablator material)이 (DT와 OR 연료층과) 섞인 것으로 나타 났다. 하이풋 레이저 펄스를 이용하여 유체역학적 불안정성을 억제함으로써 성분들이 섞이는 것을 낮춘 것이 높아진 이득 (higher yield)의 주원인이다.

또 하나의 의미 깊은 관측은 상당부분의 중성자 이득이 알 파 가열에서 나왔다는 것이다. 연료의 단위 면적당 밀도 $\rho R$ 이 높을 때 알파 입자가 연료층 안에 갇히게 되는데, 이때 축적된
에너지가 핵융합을 더 일으키고 더 많은 중성자를 만들게 된 다. 연료 이익 (에너지 생성을 에너지 입력치로 나눈 값)은 알 파 가열 이득이 압축에서 나온 이득과 같을 때를 말하고, 알파 가열은 ignition을 이루기 위한 필요조건이다. 다른 말로 하자 면, 관측된 총 이득이 압축에서 나온 이득보다 2 배 이상이라는 것이다. 2014년 3월 시점까지, 하이풋을 이용한 내파 실험은 연료에 $\sim 12 \mathrm{~kJ}$ 주입하여 $\sim 27 \mathrm{~kJ}$ 출력 에너지를 얻는 성과 를 이루었다. (그림 10)

아직은 풀어야 할 과제가 많지만, 이 실험 결과는 우리가 연 쇄 핵융합에 한걸음 더 다가간 것을 보여주는 중요한 성과이 다. 초고온 초고압의 극한 조건상의 물리를 이해하기는 쉽지 않다. 앞으로도 이 연구 프로젝트는 하이풋을 이용한 내파의 성능을 올리고 새로운 영역에 들어가기 위해 노력할 것이다. 레이저 핵융합을 통해 에너지를 얻기 위해서는 물리학과 공학 의 꾸준한 발전이 필요하다.

이 연구는 미국 에너지성의 지원 하에 국립 로렌스 리버모 어연구소에 의해 수행되었다.

This work is a collaborative effort with Laboratory for Laser Energetics (NY, USA), Los Alamos National Laboratory (NM, USA), Sandia National Laboratory (NM, USA), General Atomics (CA, USA), Massachusetts Institute of Technology (MA, USA), Atomic Weapons Establishment (UK), Commissariat à l'énergie atomique et aux énergies alternatives (France), and National Nuclear Security Administration (USA). 